\title{
The Strength of Organisational Culture: Organisational Performance in South African Schools
}

\author{
Keshni Bipath \\ University of Pretoria, South Africa \\ Email: Keshni.Bipath@up.ac.za \\ Kolawole Samuel Adeyemo
}

University of Pretoria, South Africa

Email: samuel.adeyemo@up.ac.za

\section{Doi:10.5901/mjss.2014.v5n23p2405}

\begin{abstract}
One of the more frequently cited cultural dimensions within the field of cultural research is that of cultural strength (Cameron \& Ettington, 1998). Early published works on organisational culture argue that there is an absolute need for a "strong" culture for organisations to be effective. This study has examined the contradiction between the strong school culture and academic performance in Mpumalanga Province under the Bantu Education (DET) school system. The aim of the research was to examine the dynamics of school culture strength (measured as values and norms); leadership; and the organisational performance of schools. A quantitative research approach was used. A total of 1130 questionnaires were completed by principals, School Management Team (SMT) members and educators. The findings show that the schools in Mpumalanga had a strong organisational culture, yet their performance was the lowest of all the provinces in South Africa. The paper argues: Mpumalanga schools should deconstruct their original organisational culture paradigms which evolved out of the DET system of education and that they should reconstruct their organisational cultures with renewed energy and enthusiasm for a better educated generation in the future.
\end{abstract}

Keywords: Organizational culture, Performance, School, Principal, Mpumalanga, South Africa

\section{Introduction}

Vociferous protests greeted the Bantu Education Act of South Africa when it was introduced in 1953. Its expressed aim was to educate Africans according to their ethnic identities and to provide basic literacy and numeracy skills that were needed by a burgeoning economy. Nkomo $(2009$, p.45) gives two explanations for the contrary outcomes of Bantu education: the first is that Bantu education has developed a culture of its own which is at odds with official intention; and the second is that forces external to class instruction have exerted a great influence as the official curriculum. Critics saw the act as an effort by the dominant white group to control the development of Africans and, thereby, to steer that development in a direction that would ensure their perpetual subjection.

The architects of apartheid developed their system by employing the assumptions of a "functionalist" paradigm whereby education merely responds to the demands of society's technological-occupation structure (Nkomo, 2009 p.55). Bantu education was intended to produce subservient individuals with skills that were needed to minister to the needs of the white economy rather than to develop critical leaders. However, the aim of the Department of Education and Training (DET) was to create a state of intellectual underdevelopment and dependency. Education appears to have become one of the principle disintegrative agents of the South African system.

The fractured educational history has resulted in a strongly embedded failed organisational culture that prevents leaders from recognising the need for change and adaptation to a functional organisational culture. South African schools require an infusion of a culture dimension in principals as they are the leaders who are able to create an equal, quality learning and teaching culture that could lead to functional schooling in South Africa. How did principals, SMTs and staff members rate the strength of their school culture as measured by the Organisational Culture Profile (OCP) in their school? What is the relationship between school culture and school performance in Mpumalanga? The major contribution of the study is that it is the first empirical test using the OCP and examining the perceptions of educators regarding organisational culture $(\mathrm{OC})$ and organisational performance in South African schools. The gaps that have been identified 
are research into the dynamics of stability and conflict management in the creation of organisational culture; the socioeconomic status and leadership in the creation of a strong culture; and the high performance orientation mean score in the OCP by Mpumalanga educators compared to the low matriculation (SCE) scores in Mpumalanga.

\section{Methodology}

The Organisation Culture Profile (OCP) instrument developed by Sarros, Gray, and Densten, (2002), was used to measure 7 culture dimensions and also to measure the strength of a school culture. The new shortened version of the OCP consists of a 28 term, 7 factor structure (reliabilities are shown in parentheses): competitiveness (.75); social responsibility (.74); supportiveness (.87); emphasis on rewards (.80); innovation (.80); performance orientation (.74); and stability (.66). The instrument contained the dimensions of organisational culture and properties given in Table 1, below.

Table 1: Dimensions of organisational cultures and their properties

\begin{tabular}{|l|l|}
\hline Organisational Culture Dimensions & Properties \\
\hline \multirow{4}{*}{ Competitiveness } & Achievement orientation \\
& An emphasis on quality \\
& Being distinctive - being different from others \\
& Being competitive \\
\hline \multirow{5}{*}{ Social Responsibility } & Being reflective \\
& Having a good reputation \\
& Being socially responsible \\
& Having a clear guiding philosophy \\
\hline \multirow{5}{*}{ Innovation } & Being team orientated \\
& Sharing information freely \\
\hline \multirow{5}{*}{ Emphasis on Rewards } & Being people orientated \\
& Collaboration \\
\hline & Being innovative \\
& Quick to take advantage of opportunities \\
\hline \multirow{5}{*}{ Performance Orientation } & Risk taking \\
& Taking individual responsibility \\
\hline & Fairness \\
& Opportunities for professional growth \\
& High pay for good performance \\
& Praise for good performance \\
\hline & Having high expectations for performance \\
& Enthusiasm for the job \\
& Being results oriented \\
& Being highly organized \\
\hline & Stability \\
& Being calm \\
& Security of employment \\
& Low conflict \\
\hline
\end{tabular}

\subsection{The sample}

We used the principals in ACE School Leadership Programme as a convenient sample because the environments of their schools were similar. Questionnaires were distributed to 100 principals in Mpumalanga. They had to each fill in a questionnaire and distribute the rest amongst their staff members. Questionnaires were also filled in by two Senior Management Team (SMT) members and two educators. This resulted in a total of 1130 questionnaires being completed by principals, SMT members and educators. The questionnaires were filled in by the 3 different respondent groups for reliability and validity. Of the sample of 100 schools, only 47 schools submitted complete sets of data and these were analysed. Ethical requirements were adhered to as the names of the principals, staff members and their schools were kept confidential. Questionnaires were collected and data was analysed using the SPSS 17. 


\section{Theoretical Framework}

Much popular and scholarly attention has been focused on the hypothesis that strong cultures - defined as "a set of norms and values that are widely shared and strongly held throughout the organisation" (O'Reilly \& Chatman, 1996 p.166) - enhance school performance. This hypothesis is based on the idea that organisations benefit from having highly motivated employees dedicated to common goals (Peters \& Waterman, 1982; Deal \& Kennedy, 1982; Kotter \& Hesket, 1992). In particular, the performance benefits of a strong school culture are thought to derive from three consequences of widely shared and strongly held norms and values: enhanced co-ordination and control within the school; improved goal alignment between the school and its members; and increased employee effort. In support of this argument, quantitative analyses have shown that organisations (schools) with strong cultures outperform those with weak cultures (Kotter \& Heskett, 1992; Gordon \& DiTomaso, 1992).

In a study by Bipath (2002), a questionnaire was given to 100 functional schools and 100 dysfunctional schools in South Africa and the results of the quantitative study are highlighted in the Figure 1. The figure indicates that there is a statistically significant relationship between the 5 major independent variables, namely, national/political dispensation; socio-economic status of the learners in a school; departmental inspection; school governance; and school management, on whether a school was functional or dysfunctional. The following model attempts to classify factors in layers around the core purpose of a school which is school achievement in terms of the SCE pass rate.

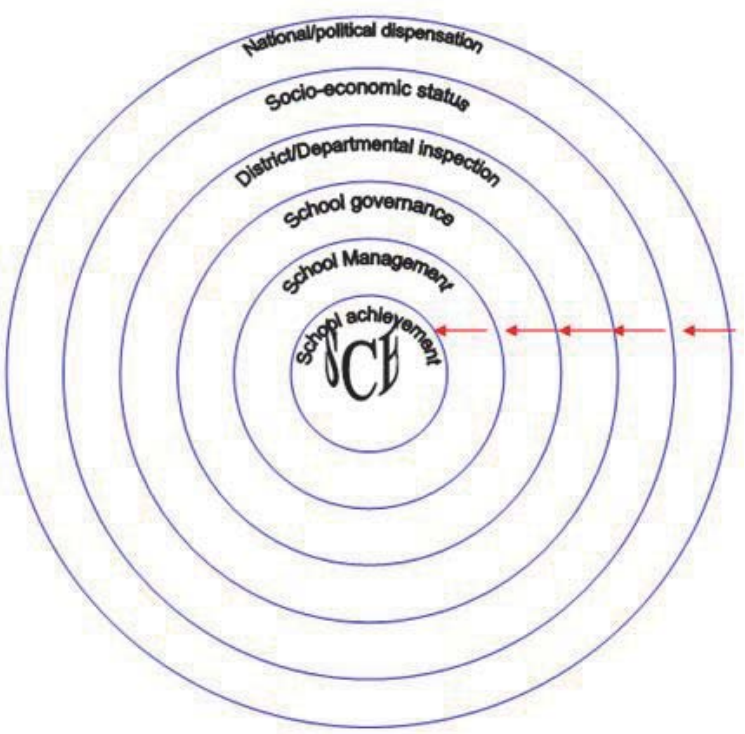

Figure 1: Factors affecting dysfunctional schools and their impact on school achievement (SCE) (Bipath, 2002:24)

The higher the socio-economic status of the learners in a school, the more likely it is that they will be associated with a functional school and the lower the socio-economic status of the learners, the more likely they will be associated with a dysfunctional school. The department under which a school was classified prior to 1994 and the odds of being classified as a dysfunctional school were greatest if the school belonged to the former Department of Education and Training (DET) - followed by the House of Representatives (HOR), the House of Assembly (HOA) and the House of Delegates (HOD). Functional schools were known to receive no visits from circuit or district representatives to discuss teaching; to provide guidance to educators; and to assess educators, while dysfunctional schools received up to three or more visits by officials from district or circuit level for WSE to check on, and discuss, various aspects of teaching and learning. Educators who teach at functional schools are seen to be able to manage and supervise themselves and do not need to be constantly supervised or assessed. If communication between educators and principal takes place on a daily or weekly basis, then the probability of the school being a dysfunctional one increases. It, therefore, appears that if communication structures in functional schools are well-established then educators know exactly what they are expected to do. In such schools meetings to discuss teaching and learning concerns occur on a monthly basis, which appear to be sufficient (Bipath, 2002 p. 64-66). The organisational culture of a school appears to be determined in terms of the ripples shown in Figure 1, above. Functional schools have a functional organisational culture whereas dysfunctional schools 
have a dysfunctional organisational culture.

Fleisch and Christie (2003 p.13) indicate that from 1994 to 1999 the SCE results reflected the continuing inequalities of the education system. The results illustrated the differences in learner performance between black and white, which could be traced back to apartheid. Table 2 shows a $20 \%$ increase in the national pass rate from $47.8 \%$ to $68.9 \%$ between 2000 and 2002. This improvement looks good, but an analysis of the results of the different provinces presents a more realistic picture. Within the same period, the number of schools with a pass rate of $0 \%$ to $20 \%$ declined from 1034 to 242 in 2002. While the difference between the figures looks phenomenal, the number of learners who passed with tertiary education endorsements remained low at 16.9\% in 2002.

In 2007 the national pass rate was $65.2 \%$ - a decline of $1.3 \%$ from the $66.6 \%$ of 2006 , which is also a $1.7 \%$ decline from the $68.3 \%$ of 2005 . From 2004 to 2007 an overall decline of $5.5 \%$ was recorded when the pass percentage was 70.7\% in 2004 (Mail and Guardian, 10-14 January 2008). In 2008 the Grade 12 learners wrote the first National Senior Certificate - based on the new curriculum, the National Curriculum Statement (NCS). The pass rate was 62.5\%, a 2.7\% decline from the $65.2 \%$ of 2007 (see Table 2).

Table 2: Representation of the decline in the SCE/NSC pass rate

\begin{tabular}{|c|c|c|c|}
\hline Years & Pass percentage & Improvement percentage & Decline percentage \\
\hline $\mathbf{2 0 0 0 - 2 0 0 2}$ & $47,8-68,9 \%$ & $21 \%$ & \\
\hline $\mathbf{2 0 0 4}$ & $70,7 \%$ & $1,8 \%$ & \\
\hline $\mathbf{2 0 0 5}$ & $68,3 \%$ & & $2,4 \%$ \\
\hline $\mathbf{2 0 0 6}$ & $66.6 \%$ & & $1,7 \%$ \\
\hline $\mathbf{2 0 0 7}$ & $65,2 \%$ & & $1,3 \%$ \\
\hline $\mathbf{2 0 0 8}$ & $62,5 \%$ & & $2,7 \%$ \\
\hline $\mathbf{2 0 0 4 - 2 0 0 8}$ & $70,7-62,5 \%$ & & $8,2 \%$ \\
\hline
\end{tabular}

The inconsistencies in the pass rates have raised alarms, not only in the National and Provincial Departments of Education but also in other sectors of civil society. The present skills shortage in South Africa can be attributed to the slow rate at which learners leave high school and enter universities and other institutions of higher learning. This situation is an indication that the number of economically active individuals, particularly the youth, is declining. On the whole, it means that the government is working at a loss because output (individuals becoming economically active) is not compatible with input (the amount of money spent on the education of each learner in the country). It is, therefore, important that the leadership in schools be trained in organisational culture in order to make a positive contribution to the improvement of the NSC results; it is also necessary to infuse an organisational culture in schools to gauge its positive impact.

O'Rielly (1989) gives two reasons why strong cultures are valuable: the interrelationship between organisational culture and strategy; and the increased commitment of employees to the organisation. He argues that these provide a competitive edge and that, in this way, strong culture organisations have an advantage over their competitors. Schein (1984) contests the notion of an absolute need for a strong culture to achieve effectiveness by arguing that the relationship must be much more complex. He points to the need for a contingency or situational approach and he maintains that the critical variables are "contents of the culture and the degree to which its solutions fit the problems posed by the environment" (Schein, 1984 p.7).

Peters and Waterman (1982 p. 76) emphasise the importance of having a strong culture by suggesting that the dominance and coherence of culture has proved to be an essential quality of excellent organisations. However, Saffold (1988 p. 552) presents five weaknesses inherent in the strong culture hypothesis: the assumption of a unitary culture; the ambiguity of strength as a measure of culture; dependence upon composite culture profiles; insufficient attention to culture performance links; and the use of inadequate methodologies. Alvesson (2002) summarises four views on the relationship between organisational culture and performance: the strong-culture thesis, where a strong culture leads to high performance; the exact opposite, where high performance leads to strong culture; the contingency approach, where certain cultures are appropriate and necessary; and, finally, the "adaptive cultures", which are the key to better performance through their ability to respond quickly to environmental changes.

Culture's role in performance can be seen from another angle where strong culture has been observed to clarify an organisation's goals and practices. Employee uncertainty with regard to the risks involved in taking some or other action can be reduced and the employees can interact more rapidly with one another (Burt, Gabbay, Holt and Moran, 1994). Denison (1990) also found that organisations with participative cultures perform better than those without a culture. 
However, Lewis (1994) concludes her study of a tertiary institution in Australia by suggesting that behaviour is the only thing that can directly affect an organisation's performance. Lewis points out that "while behaviour may be one embodiment of culture, culture is certainly not the only determinant of behaviour" (Lewis, 1994 p. 51).

The performance benefits of a strong culture are thought to derive from three consequences of having widely shared, and strongly held, norms and values: enhanced coordination and control within the school; improved vision alignment between the principal and all stakeholders; and increased educator effort (Sorenson, 2002). Sorensen (2002 p. 73) explains that while it is possible that strong culture schools may be better at choosing appropriate strategies, theories of culture create a focus on the positive impact that a strong culture has on the execution of routines. Theorists have put forward three interrelated explanations for the performance benefits of strong cultures (Kotter \& Heskett, 1992). Firstly, widespread consensus and endorsement of organisational values and norms facilitate social control within a school. When there is broad agreement that certain behaviours are more appropriate than others, violations of behavioural norms may be detected and quickly corrected and corrective actions are more likely to come from other staff members, regardless of their place in the formal hierarchy. Informal social control is, therefore, likely to be more effective and cost less than formal control structures (O'Reilly \& Chatman, 1996). Secondly, strong school cultures enhance goal alignment. With clarity about school goals and practices, employees face less uncertainty about the proper course of action when they are faced with unexpected situations and they can react appropriately. Goal alignment also facilitates coordination as there is less room for debate between different parties about the organisation's best interests. Finally, strong cultures can enhance employees' motivation and performance because they perceive that their actions are freely chosen.

While some see attempts to measure organisational cultures and their effects on organisations as highly problematic (Siel \& Martin, 1990; Alvesson, 1993), much research starts from the assumption that culture is a measurable characteristic of organisations (O'Reilly \& Chatman, 1996). O'Reilly and Chatman maintain that organisational culture is "a system of shared values (that define what is important) and norms that define appropriate attitudes and behaviours for organisational members (how to behave)" (1996 p. 160). A culture can be considered strong if those norms and values are widely shared and intensely held throughout the organisation. This definition of culture strength - in contrast to some others - entails no assumptions about which values and norms might enhance organisational performance (Sorensen, 2002 p. 72). One of the key consequences of a strong culture is that it increases behavioural consistency across the board in individuals in a school. Organisational culture defines a normative order that serves as a source of consistent behaviour within the organisation. Organisational culture frames people's interpretation of organisational events and basic assumptions about organisational processes. Schein emphasizes that organisational cultures "provide group members with a way of giving meaning to their daily lives, setting guidelines and rules for how to behave, and most important, reducing and containing the anxiety of dealing with an unpredictable and uncertain environment" (1991 p. 15).

Schein's seminal work proposes that, in large measure, a leader creates the culture - a view shared by Daymon (2000) and Martin, Sitkin and Boehm (1985). Organisational culture can, simultaneously, be both an antecedent and an intervening variable. Whatever the relationship, there is irrefutable evidence that strong organisational cultures are associated with strong and competent leadership. Leaders in these cultures are role models who espouse organisational goals and encourage employee commitment to the organisation's purpose and vision (Sarros et al., 2002 p. 2).

Organisational culture only arises when the individual assumptions of a leader leads to shared experiences that solve the team's problems of external survival and internal integration. Organisational culture is created by shared experience, but it is the principal who initiates this process by imposing his/her beliefs, values, and assumptions at the outset (Schein, 2004 p. 225). Schein (2004 p. 22) believes that leadership and organisational culture are two sides of the same coin in that leaders first create cultures when they create groups and organisations. Once cultures exist they determine the criteria for leadership and, thus, determine who will/will not be a leader. But if elements of a culture become dysfunctional, it is the unique function of the leader to be able to perceive the functional and dysfunctional elements of the existing culture and to manage cultural evolution and change in such a way that the group can survive in a changing environment.

The bottom line for leaders is that if they do not become conscious of the cultures in which they are embedded, those cultures will manage them. According to Schein, cultural understanding is essential for principals if they are to lead (2004 p. 23). Culture, as defined by Schein (2004 p. 17), is a pattern of shared basic assumptions that is learned by a group as it solves its problems in terms of external adaptation and internal integration which has worked well enough to be considered valid and, therefore, to be taught to new members as the correct way to perceive, think and feel in relation to those problems. School culture is, therefore, created when difficulties are faced and problems are solved continuously. When the school faces a problem and finds a solution that works repeatedly, this is later taken for granted and becomes a basic assumption that that is the way things are done around here. Culture is deep, pervasive, complex, patterned and morally neutral. 


\section{Findings and Discussion}

The perceptions of principals, SMTs and educators suggested that schools in Mpumalanga had strong cultures as the strength of the culture $(3<\mathrm{C}$ mean $<4)$ was indicative of a strong culture. The 7 dimensions of Organisational Culture (OC) measured by the OCP instrument was performance orientation $(M=3,7987)$; supportiveness $(M=3,6819)$; competitiveness $(M=3,6519)$; social responsibility $(M=3,5877)$; emphasis on rewards $(M=3,5081)$; innovation ( $M=$ $3,4649)$ and stability $(M=3,3874)$. The contradiction of a high OC compared to the low performance scores was at first depressing and then became an exciting puzzle to solve. Was OC a 'double-edge sword' that dictated the level and paradigm of the perceptions of the respondents? This puzzle slowly unravelled while analysing the reasons for the high scores of the respondents (see Table 3).

Table 3: A comparison of the mean scores of the culture dimensions amongst the principals, SMTs and educators

\begin{tabular}{|l|l|l|l|l|l|l|}
\hline & $\begin{array}{c}\text { Mean } \\
\text { (Score) }\end{array}$ & & $\begin{array}{c}\text { Mean } \\
\text { (Score) }\end{array}$ & & $\begin{array}{c}\text { Mean } \\
\text { (Score) }\end{array}$ & \\
\hline $\begin{array}{l}\text { Principal-performance } \\
\text { orientation }\end{array}$ & 3.8883 & $\begin{array}{l}\text { SMT-performance } \\
\text { orientation }\end{array}$ & 3.7632 & $\begin{array}{l}\text { Teacher-performance } \\
\text { orientation }\end{array}$ & 3.7472 & $\begin{array}{l}\text { Tot-performance } \\
\text { orientation }\end{array}$ \\
\hline Principal-supportiveness & 3.8564 & SMT-supportiveness & 3.6513 & Teacher- competitiveness & 3.6164 & Tot-supportiveness \\
\hline Principal competitiveness & 3.7287 & SMT-competitiveness & 3.6117 & Teacher-supportiveness & 3.5417 & Tot-competitiveness \\
\hline Principal-social responsibility & 3.6596 & SMT-social responsibility & 3.5770 & Teacher-social responsibility & 3.5289 & Tot-social responsibility \\
\hline Principal-emphasis on rewards & 3.6543 & SMT-emphasis on rewards & 3.5047 & Teacher -innovation & 3.3849 & Tot-emphasis on rewards \\
\hline Principal -innovation & 3.6117 & SMT -innovation & 3.3994 & Teacher-emphasis on rewards & 3.3674 & Tot -innovation \\
\hline Principal-stability & 3.5426 & SMT-stability & 3.3879 & Teacher-stability & 3.2362 & Tot-stability \\
\hline
\end{tabular}

The findings of the OCP, reflected in Table 3, show that performance orientation, which consisted of having high expectations for performance; enthusiasm for the job; being results orientated; and being highly organised, displayed the highest mean score of all groups of respondents - a contradiction because the worst performing schools in South Africa, on average, are situated in Mpumalanga. There is a very slight variance in the mean scores amongst the principals, SMT and educators. The respondents acknowledged that they have high expectations for performance; they are enthusiastic about their jobs; they are results orientated; and they are highly organised. Within their paradigm, they are functioning in a dysfunctional culture and they expect good results. They are working hard at their jobs but their standard for hard work is far below mediocrity. Over a period of time the culture solidifies and becomes frozen and becomes almost impossible to change. The culture is entrenched in the old DET systems and the literature shows that the ineffective DET system was designed to systematically deprive the masses of a good academic education. The purpose of Bantu education was, ostensibly, to school Africans within their own cultural groups and patterns, while its actual goal was to produce a semiliterate industrial force to meet an expanding economy (Nkomo, 2009).

The principals and SMTs rated supportiveness which consists of being team orientated; sharing information freely; being people orientated; and collaboration as second whereas the teachers rated competitiveness which consists of achievement orientation; an emphasis on quality being distinctive, i.e., being different from others; and being competitive as second. This is no surprise as members of management feel that they share information and are people orientated and collaborative as they work with teams of educators. Due to the educators being more involved with teaching and learning in the classroom and working hard to teach and assess learning outcomes per learning area, they rate competitiveness and achievement orientation as second.

The third culture dimension rating is the opposite of the second. The SMTs rate 'being competitive' third whereas the educators rate 'being supportive' third. This could also be the result of educators perceiving teacher unions to be more supportive than the SMTs. One could also argue that the educators feel that the SMTs do not allow for team orientation, collaboration, sharing information freely and being people-orientated due to the performance management system which scores educators on orientation; places an emphasis on quality; on being distinctive, i.e., being different from others and being competitive. The Integrated Quality Management System (IQMS) is a teachers' appraisal system which awards a $1 \%$ salary increase for achieving $50 \%$ in 9 different areas of teaching and learning. Teachers may also be more inclined to be competitive in terms of promotions rather than supporting one another.

Social responsibility was rated fourth by all respondents in all three categories which displays that there is consensus that being reflective; having a good reputation; being socially responsible; and having a clear guiding philosophy is fourth and in the middle of the ratings in the culture dimensions. In a society that seems to have lost its moral compass, this score was very encouraging. With social problems, such as HIVIAIDS, crime, unemployment and 
poverty which has resulted in child-headed households, educators need to be socially responsible and work towards a clear guiding philosophy. Contrary to this score, Mpumalanga has one of the highest teenage pregnancies and drop-out rates amongst adolescents.

Principals and SMTs rated the emphasis on rewards which consists of fairness; opportunities for professional growth; high pay for good performance; and praise for good performance fifth, whereas educators rated innovation which consists of being innovative; quick to take advantage of opportunities; risk-taking and taking individual responsibility fifth. This is surprising as educators earn a set salary and performance does not guarantee large bonuses. Because Section 21 schools determine their own budgets, the need for an emphasis on rewards for good teaching is required. In education opportunities for professional growth are poor but with the provision of funding by the Department of Education for ACE School Leadership licences for SMTs, it is not unlikely that the SMTs would rate rewards higher than innovativeness.

Innovation which consists of being innovative; taking advantage of opportunities; risk-taking; and taking individual responsibility was sixth in the ranking and is also a cause for concern. Is the curriculum so rigid that it does not allow for innovation, risk-taking and individual responsibility? Does responsibility and risk-taking prevent innovation in curriculum delivery? Are educators so caught up with assessment tasks that they have no time for innovation in the classroom? The new National Curriculum Policy is so crowded with learning outcomes per learning area that educators have no time to be innovative. Another reason for this is the move to purchase learner workbooks which are published in terms of the NCS. The educator uses the learning material as is and there is no time for innovation as publishing houses have capitalised on the new curriculum and planned workbooks that has simplified the planning and preparation work of the educators. Besides, innovation was never part of educators training and development at training colleges.

Stability $(M=3,3874)$ was ranked the lowest which is a cause of concern and requires further research. Stability consists of being calm; having security of employment; and showing low conflict. Further research could determine whether teacher unions, safety and security and conflict management are reasons for instability in schools. Do principal preparation programmes contain information on conflict management? This could also suggest that conflict between educators and SMTs is rife and that due to the many curriculum and policy changes, educators do not find the school a stable environment. There is no consistency between policy and practice and just when educators are getting to grips with something new, another change is made.

An essential feature of these findings is the realisation that the respondents are so firmly embedded in a dysfunctional culture that they scored themselves highly when, in fact, they were performing below mediocrity. In terms of Schein's definition of culture (2004:17) the pattern of shared basic assumptions - that is learned by a group as it solved its problems of external adaptation and internal integration and that has worked well enough to be considered valid and may, therefore, to be taught to new staff members as the correct way to perceive, think and feel in relation to those problems should have occurred within the last 20 years of democracy. According to Schein, school culture is created when difficulties are faced and problems are solved continuously. When a school faces a problem and finds a solution that works repeatedly, this is later taken for granted and becomes a basic assumption that that is the way things are done around here. It seems that in Mpumalanga schools there was no clear external adaptation of new ideas and visions and, therefore, internal integration did not occur. This has led to a dysfunctional culture when the schools face the problem of a high failure rate. The dysfunctional culture needs to be unlearnt or thawed; then to be changed positively and refrozen so that performance will be enhanced by 'the way things are done here.'

The findings show that the culture dimensions are rigid and even leaders do not realise that they need to transform these firmly entrenched bad habits. Performance orientation which consists of having high expectations for performance; being enthusiastic about the job; being results-orientated; and being highly organised displayed the highest mean score in all the groups of respondents. This indicates that respondents thought they were enthusiastic and highly organised while, in fact, they did not realise that they were not enthusiastic about teaching and learning for improvement and excellence. Although they scored themselves as highly organised by their standards, the SCE syllabus was not covered, monitored or assessed by March 2010 (Interview with a group of principals during member checking process).

\section{Conclusion}

The study has examined the contradiction between school culture and school performance in Mpumalanga which reflects the damage that was caused by an ineffective DET system that was designed to create a skilled labour force. This past organisational culture was so strong that unfreezing, changing and refreezing the culture will take time and the leaders need to be trained in this process to create a positive teaching and learning culture for the improvement of, and excellence in, education. The study proves that organisational culture is likely to be taken for granted and that dysfunctional organisational culture is embedded in the organisation's routines and rituals and that staff members cannot see that it is wrong. Johnson and Scholes argue that this embedded culture is a "two-edged sword" (1997:141): it is often 
a strength in relation to the delivery of current strategies since this tacit knowledge is not easy to imitate but is also, potentially, a major weakness as it may prevent managers from recognising the need for change and from ensuring that tacit knowledge in the organisation is challenged and that the learning of new competences occurs. The many changes in the curriculum; the new policies regarding continuous professional development; the IQMS; and the new legislation that have occurred since 1994 were merely 'rearranging the deckchairs on the Titanic.' The existing organisational culture in Mpumalanga schools is dangerous and will result in the sinking of an educational system and loss of an educated generation if it is not addressed urgently. We argue that Mpumalanga schools should deconstruct their original organisational culture paradigms which have evolved out of the DET system of education and that they should reconstruct a culture with renewed energy and enthusiasm for a future educated generation.

\section{References}

Alvesson, M. (1993). Culture perspectives on organisations. New York: Cambridge University Press.

Bipath, K. (2002). Differentiating between functional and dysfunctional schools. Unpublished M.Ed Dissertation. Rand Afrikaans University, Johannesburg, South Africa.

Burt, R. S., Gabbay, S. M., Holt, G. \& Moran, P. (1994). 'Contingent organisation as a network theory: The culture performance contingency function', ACTA Sociologica, 37: 345- 370.

Cameron, K. S. \& Ettington, D. R. (1988). "The conceptual foundations organizational culture." Higher Education: Handbook of Theory and Research,(356-396). New York: Agathon.

Daymon, C. (2000). 'Culture formation in a new television station: A multi-perspective analysis', British Journal of management, 11(2): 121-135.

Deal, T. \& Kennedy, A. (1982). Corporate cultures. Reading, MA: Addison-Wesley.

Denison, D. (1990). Corporate Culture and Organisational Effectiveness. New York: John Wiley.

Fleisch, B. and Christie, P. (2004). Structural Change, Leadership and School Effectiveness/Improvement: Perspectives from South Africa. Discourse: Studies in the Cultural Politics of Education. Vol. 25(1), March 2004. Carfax Publishing.

Gordon, G. G. \& DiTomaso, N. (1992). 'Predicting corporate performance from organisational culture', Journal of Management Studies, 29:783-799.

Johnson, G. \& Scholes, K. (1997). Exploring corporate strategy. London: Prentice Hall.

Kotter, J. P. \& Heskett, J. L. (1992). Corporate culture and performance. New York: The Free Press.

Lewis, D. S. (1994). 'Organisational change: Relationship between reactions behaviour and organisational performance', Journal of Organisational Change Management, 75(5):41-55.

Martin, J., Sitkin, S. B. \& Boehm, M. (1985). 'Founders and the elusiveness of a cultural legacy'. In: Martins, J. (ed). Organisational Culture: Mapping the Terrain. London: Sage Publications.

Nkomo, M. O. (2009). The contradictions of Bantu Education. In: Blair, E.E.; Miller, R.B. \& Mara, C.T. 9eds). Education and War. Harvard Education Review Reprint Series, No.45.

O'Reilly, C. A., Chatman, J. \& Caldwell, D. F. (1996). 'People and organisational culture: A profile comparison approach to assessing person-organisation fit', Academy of Management Journal, 34(3):487-516.

O'Reilly, C. A. (1989). 'Corporate, culture and commitment. Motivation and social control in organisations', California Management Review, 31(4):9 -25.

O'Reilly, C. A. \& Chatman, J. A. (1996). 'Culture as social control: Corporations, culture and commitment'. In Straw B. M. \& Cummings, L. L. (eds). Research in Organisational Behaviour, 18:157-200.

Peters, T. \& Waterman, R. (1982). In search of excellence. New York : Harper and Row.

Saffold, G. (1988). 'Culture traits, strength, and organisational performance. Moving beyond "strong" culture', Academy of Management Review, 13:546-558.

Sarros, J. C., Gray, J. \& Densten, I. L. (2002). 'Leadership and its impact on organisational culture', International Journal of Business Studies, 10(2):1-26.

Schein, E. H. (1984). 'Coming to a new awareness of organisational culture'. Sloan Management Review, Winter.

Schein, E. H. (1991). 'What is culture?'. In Frost, P., Moore, L., Louis, M., Lunberg, C. \& Martins, J. (eds). Reframing organisational culture. Newbury Park, CA: Sage Publications.

Schein, E. H. (2004). Organisational culture and leadership. San Francisco: Jossey-Bass.

Siehl, C. \& Martin, J. (1990). 'Organisational culture: A key to financial performance?' In: Schnieder, B. (ed). Organisational climate and culture. San Francisco: Jossey-Bass. 79-104.

Sorenson, J. B. (2002). The strength of corporate culture and the reliability of firm performance. Administrative Science Quarterly, 47 (2002), 70-91 